\section{(6) OPEN ACCESS}

\title{
Fractional flow reserve versus angiography for guiding percutaneous coronary intervention: a meta-analysis
}

\author{
Dongfeng Zhang, Shuzheng Lv, Xiantao Song, Fei Yuan, Feng Xu, Min Zhang, \\ Shuai Yan, Xingmei Cao
}

- Additional material is published online only. To view please visit the journal online (http://dx.doi.org/10.1136/ heartjn-2014-306578).

Department of Cardiology, Beijing An Zhen Hospital, Capital Medical University, Beijing Institute of Heart Lung and Blood Vessel Disease, Beijing, China

\section{Correspondence to} Shuzheng Lv, Department of Cardiology, Beijing An Zhen Hospital, Capital Medical University, Beijing Institute of Heart Lung and Blood Vessel Disease, Anzhenli Avenue, Chao Yang District, Beijing 100029, China; Ivshuzheng_2013@163.com

SL and XS contributed equally to the design of the article.

Received 30 July 2014 Revised 18 November 2014 Accepted 9 December 2014 Published Online First 30 January 2015

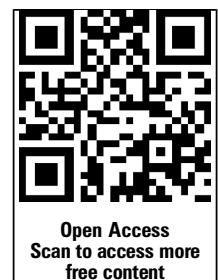

CrossMark

\footnotetext{
To cite: Zhang D, Lv S, Song $X_{\text {, et }}$ al. Heart 2015;101:455-462.
}

ABSTRACT

Objectives The purpose of this study was to investigate whether fractional flow reserve (FFR) should be performed for patients with coronary artery disease (CAD) to guide the percutaneous coronary intervention (PCI) strategy.

Background $\mathrm{PCl}$ is the most effective method to improve the outcomes of CAD. However, the proper usage of $\mathrm{PCI}$ has not been achieved in clinical practice. Methods A meta-analysis was performed on angiography-guided $\mathrm{PCl}$ and FFR-guided $\mathrm{PCl}$ strategies. Prospective and retrospective studies were included when research subjects were patients with $C A D$ undergoing $\mathrm{PCl}$. The primary endpoint was the rate of major adverse cardiac events (MACE) or major adverse cardiac and cerebrovascular events (MACCE). Secondary endpoints included death, myocardial infarction (MI), repeat revascularisation and death or MI.

Results Four prospective and three retrospective studies involving 49517 patients were included. Absolute risks of MACE/MACCE, death, MI, revascularisation and death or MI for angiography-guided PCl and FFR-guided PCI were $34.8 \%$ vs $22.5 \%, 15.3 \%$ vs $7.6 \%, 8.1 \%$ vs $4.2 \%, 20.4 \%$ vs $14.8 \%$, and $21.9 \%$ vs $11.8 \%$, respectively. The meta-analysis demonstrated that FFRguided PCI was associated with lower MACE/MACCE (OR: $1.71,95 \% \mathrm{Cl} 1.31$ to 2.23 ), death (OR: 1.64 , 95\% Cl 1.37 to 1.96$)$, MI (OR: $2.05,95 \% \mathrm{Cl} 1.61$ to 2.60), repeat revascularisation (OR: $1.25,95 \% \mathrm{Cl} 1.09$ to 1.44 ), and death or MI (OR: $1.84,95 \% \mathrm{Cl} 1.58$ to 2.15) than angiography-guided $\mathrm{PCl}$ strategy.

Conclusions This meta-analysis supports current guidelines advising the FFR-guided PCI strategy for CAD. $\mathrm{PCl}$ should only be performed when haemodynamic significance is found.

\section{INTRODUCTION}

To date, coronary artery disease (CAD) remains the leading cause of death worldwide. ${ }^{1}$ The standard technique for the diagnosis and treatment of anatomic CAD has been coronary angiography. However, the most important prognostic factor in patients with CAD is the presence and extent of inducible ischaemia. ${ }^{2}$ Performing percutaneous coronary intervention (PCI) for stenoses that are anatomically worrisome but not functionally significant will diminish the benefit of relieving ischaemia by exposing the patients to an increased stent-related risk.
Fractional Flow Reserve (FFR), defined as the ratio of pressure distal to the stenosis and aortic pressure after induced maximal hyperaemia, can identify the haemodynamically significant lesions. ${ }^{3}{ }^{4}$ In patients with multivessel CAD, the FAME (Fractional Flow Reserve vs Angiography for Multivessel Evaluation) study indicates that FFR-guided revascularisation relates lower rates of adverse events with lower healthcare costs than angiography-guided revascularisation. ${ }^{5}$ FFR is now considered the gold standard for guiding percutaneous coronary revascularisation with class IA European Society of Cardiology and class IIA American Heart Association practice guideline recommendations. ${ }^{67}$ The normal value of FFR is 1.0 , regardless of the patient or the specific vessel studied. Coronary lesions with FFR $<0.75$ are almost always functionally significant, whereas stenoses with FFR $>0.80$ are rarely associated with inducible ischaemia. ${ }^{4}$

Despite the apparent benefits, the adoption of FFR into daily clinical practice has been limited due to the invasive nature of the procedure, the need for pharmacologic vasodilation, and risks related to instrumentation of the coronary arteries.

Almost all studies comparing an angiographyguided PCI strategy with an FFR-guided one in patients with CAD are of a small scale, and most of them are retrospective studies which do not have a high evidence level. We performed this metaanalysis of contemporary clinical trials that compared the two strategies in patients with CAD to identify the advantages of FFR for guiding PCI strategy.

\section{METHODS}

Data sources and study selection

PubMed, Embase and Cochrane Controlled Trials Register searches were performed to identify articles published in English before September 2014 on angiography-guided PCI versus FFR-guided PCI for the treatment of CAD. The following medical subject headings and search terms were used: 'fractional flow reserve', 'coronary artery disease', 'revascularization', 'percutaneous coronary intervention'. The references of selected articles and relevant reviews were screened for potentially suitable references by two independent investigators (SY and XC).

An initial screening of titles or abstracts was conducted, followed by full-text reviews. Studies were included if they met the following criteria: (1) a 
study was eligible regardless of whether patients were referred for suspected or known CAD; (2) data had to be stratified to at least two PCI strategies for CAD, angiography-guided PCI and FFR-guided PCI and (3) studies that reported endpoint data of interest. Studies were excluded if they met any one of the following criteria: (1) studies using the same patient sample, (2) ongoing or unpublished studies and (3) data published only as an abstract or as conference proceedings. We scrutinised all eligible reports for potential overlap in the study populations to retain only the largest and latest of the overlapping studies. Differences in investigator assessments of articles were resolved by discussion with a third investigator (DZ).

\section{Data extraction}

For each eligible study, we documented the first author, year of publication, study characteristics, patient characteristics and outcomes. Data were abstracted from text, tables and figures by two investigators (FX and MZ). Authors of studies were contacted when results were unclear or when relevant data were not reported. Divergent assessments were resolved by discussing with a third investigator (FY). Study information was recorded as follows: study design, quality indicators, baseline clinical characteristics and clinical outcomes.

\section{Definition}

The primary endpoint was the rate of major adverse cardiac events (MACE) or major adverse cardiac and cerebrovascular events (MACCE) during the longest follow-up. Secondary endpoints included long-term death, myocardial infarction (MI) and revascularisation. Death or MI, which was an important clinical variable, was concluded as a secondary endpoint as well. MACE, MACCE, death, MI and revascularisation were defined as reported in each study.

\section{Quality assessment}

The quality of prospective and retrospective studies was assessed, respectively.

\section{Statistical analysis}

All statistical analysis was performed using Review Manager 5.1 (Cochrane Center, Denmark). OR and 95\% CI were used as summary statistics. Heterogeneity across studies was analysed using $\mathrm{I}^{2}$. An $\mathrm{I}^{2}$ statistic value of $>50 \%$ was defined as statistical heterogeneity. Pooled estimates were first calculated using the
Mantel-Haenszel fixed-effects model, whereas the DerSimonian and Lair random-effects model was used if there was heterogeneity. Funnel plots were used to assess potential publication bias.

Exploring heterogeneity is critical for understanding the factors that influence endpoints. The following methods were used to explore sources of heterogeneity: (1) subgroup analysis (prospective and retrospective groups) and (2) sensitivity analysis performed by repeating analyses following the removal of each study, one at a time. All p values were two-tailed, with statistical significance set at $\mathrm{p}<0.05$.

This study was performed according to the Preferred Reporting Items for Systematic Reviews and Meta-Analyses (PRISMA) statement.

\section{RESULTS}

\section{Study characteristics}

Seven studies including 49517 patients met our inclusion criteria, including four prospective ${ }^{5-10}$ and three retrospective studies $^{11-13}$ published between 2005 and 2014. Details of the screening process for eligible studies are shown in figure 1 . The study and population characteristics and a list of all studies included in the meta-analysis are presented in table 1.

Eligible patients in the FAME study have lesions that are $\geq 50 \%$ narrowed and that the investigator feels require stenting in $\geq 2$ major epicardial vessels. ${ }^{5}$ The other study concluded patients with stable angina and $\geq 2$ single lesions located in two major epicardial coronary arteries, or one major epicardial vessel and a branch originating from a major epicardial vessel. ${ }^{9}$ One study compared PCI strategies in patients with coronary bifurcation lesions with jailed side branches after successful drug eluting stent (DES) implantation at the main branches. ${ }^{8}$ One study compared angiography-guided PCI and FFR-guided PCI strategy in patients with coronary stenosis in small vessels. ${ }^{13}$ Another study compared the two strategies in patients with at least one intermediate stenosis of an arterial or a venous bypass graft. ${ }^{11}$ Quality assessment results are detailed (see online supplementary table S1 and S2). The assessment of the funnel plot suggested no publication bias (see online supplementary figure S1).

Angiography-guided PCI was the more frequently performed strategy (44 697 of 49517 patients, 90.3\%). Baseline characteristics of the included studies are presented in detail (see online supplementary table S3). Additionally, summaries of baseline mean/percentages are provided for the included studies. Compared with the angiography-guided PCI group, patients in
Figure 1 Flow diagram of study inclusion and exclusion criteria.

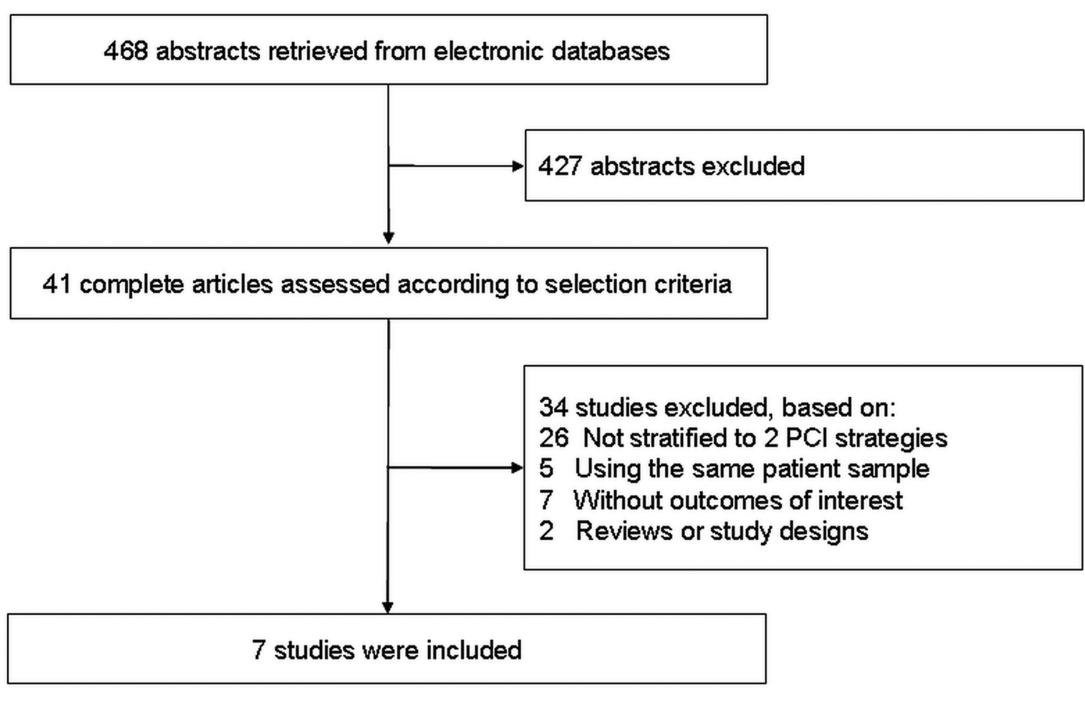




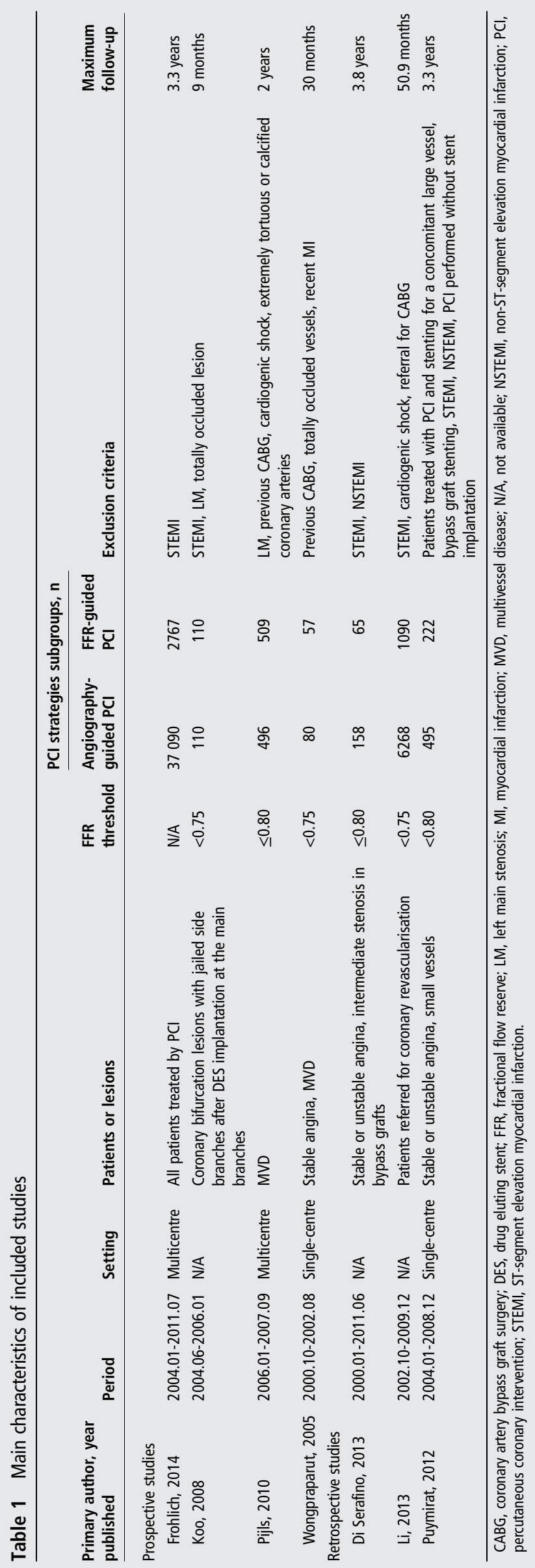

the FFR-guided PCI group consisted of fewer current smokers (18.2\% vs $19.3 \%)$, more patients with hypertension $(67.0 \%$ vs $59.6 \%$ ), and used less stents per patient (1.03 vs 1.67$)$. No differences were observed regarding age (65.8 vs 67.8 years), sex (70.7\% vs $73.7 \%)$, diabetes $(25.8 \%$ vs $24.5 \%)$, hypercholesterolaemia $(61.1 \%$ vs $80.8 \%)$, DES $(33.2 \%$ vs $67.2 \%)$, and contrast agent amount (274.2 vs $297.3 \mathrm{~mL})$.

\section{Main outcomes}

In the study by Di Serafino et al, MACCE was defined as the composite of all-cause death, non-fatal MI, target vessel failure, and cerebrovascular accidents. In summary, MACE/MACCE was reported in six studies. Absolute risks of MACE/MACCE were $34.8 \%$ for angiography-guided PCI and 22.5\% for FFR-guided PCI. The use of FFR led to a reduction of absolute risk by $12.3 \%$. Signs of heterogeneity were found across trials $\left(I^{2}=55 \%, 95 \%\right.$ CI $0 \%$ to $\left.82 \%\right)$, and a random effects model was used. Compared with angiography-guided PCI, FFR-guided PCI was associated with an obviously decreased MACE/MACCE (OR: $1.71,95 \%$ CI 1.31 to $2.23, \mathrm{p}<0.001$ ) (figure 2).

Long-term death for both strategies was reported in six studies. Absolute risks of death were $15.3 \%$ for angiographyguided PCI and 7.6\% for FFR-guided PCI. The use of FFR led to a reduction of absolute risk by $7.7 \%$. Heterogeneity was not found across trials $\left(\mathrm{I}^{2}=0 \%, 95 \%\right.$ CI $0 \%$ to $\left.79 \%\right)$, and a fixed-effects model was used. FFR-guided PCI was associated with a decreased follow-up death in comparison with the angiography-guide PCI strategy (OR: 1.64, 95\% CI 1.37 to 1.96, p <0.001) (figure 3). Additionally, inhospital mortality reported in the study by Frohlich et al was used for a second analysis because the long-term mortality was not available (OR: $1.68,95 \%$ CI 1.41 to $2.01, \mathrm{p}<0.001)$.

Absolute risks of MI were $8.1 \%$ for angiography-guided PCI and $4.2 \%$ for FFR-guided PCI. The use of FFR led to a reduction of absolute risk by $3.9 \%$. No heterogeneity was found among the studies $\left(\mathrm{I}^{2}=44 \%\right.$, 95\% CI $0 \%$ to $\left.79 \%\right)$, and a fixed-effects model was used. The difference between two groups was significant (OR: 2.05, 95\% CI 1.61 to 2.60, $\mathrm{p}<0.001)$, which indicates that the angiography-guided PCI may increase the risk of MI (figure 4).

In summary, the absolute risk of revascularisation was $20.4 \%$ for angiography-guided PCI and $14.8 \%$ for FFR-guided PCI. The use of FFR led to a reduction of absolute risk by $5.7 \%$. No heterogeneity was found among the studies $\left(\mathrm{I}^{2}=48 \%, 95 \%\right.$ CI $0 \%$ to $80 \%$ ), and a fixed-effects model was used. FFR-guided PCI was associated with a decreased repeat revascularisation compared with the angiography-guided PCI strategy (OR: 1.25, 95\% CI 1.09 to $1.44, \mathrm{p}=0.002$ ) (figure 5). Three articles reported on any revascularisation (OR: $1.76,95 \%$ CI 1.18 to $2.63, \mathrm{p}=0.005$ ), while another three provided the details of target vessel revascularisation (TVR) (OR: 1.31, 95\% CI 0.90 to $1.91, \mathrm{p}=0.16$ ).

Four studies provided information regarding death or MI. The absolute risks of death or MI were $21.9 \%$ for angiographyguided PCI and $11.8 \%$ for FFR-guided PCI. The use of FFR led to a reduction of absolute risk by $10.2 \%$. Signs of heterogeneity were not found across trials $\left(\mathrm{I}^{2}=0 \%, 95 \%\right.$ CI $0 \%$ to $\left.85 \%\right)$, and a fixed effects model was used. FFR-guided PCI was associated with an obvious decrease in long-term death or MI compared to the angiography-guided PCI strategy (OR: 1.84 , 95\% CI 1.58 to $2.15, \mathrm{p}<0.001$ ) (figure 6).

\section{Sensitivity analysis}

Subgroup analysis showed no signs of heterogeneity after excluding the retrospective studies $\left(\mathrm{I}^{2}=48 \%\right.$, 95\% CI $0 \%$ to 


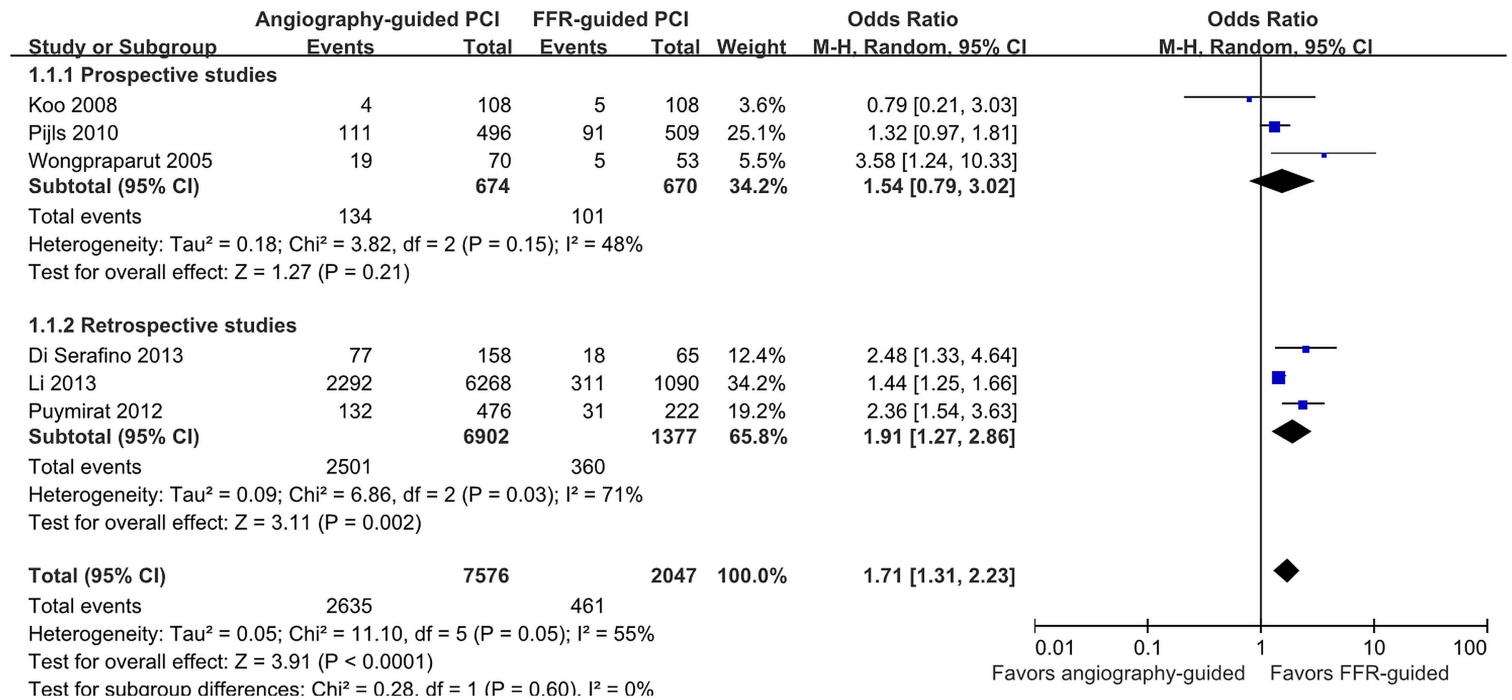

Figure 2 Angiography-guided percutaneous coronary intervention (PCl) versus fractional flow reserve-guided PCI major adverse cardiac events/ major adverse cardiac and cerebrovascular events.

85\%). Angiography-guided PCI was associated with an increased MACE/MACCE in comparison with FFR-guided PCI strategy (OR: $1.41,95 \%$ CI 1.06 to $1.88, \mathrm{p}=0.02$ ). We also performed sensitivity analyses by repeating analyses following the removal of each study one at a time (data not shown). The heterogeneity of MACE/MACCE no longer existed when the study by Puymirat et al was removed $\left(\mathrm{I}^{2}=40 \%, 95 \%\right.$ CI $0 \%$ to $\left.78 \%\right)$. Nonetheless, FFR-guided PCI was still associated with a better outcome of MACE/MACCE than the angiography-guided PCI strategy (OR: $1.47,95 \%$ CI 1.30 to $1.66, \mathrm{p}<0.001$ ) (see online supplementary figure S2). Sensitivity analyses were also performed by removing the study with the largest sample size (table 2).

\section{DISCUSSION}

This meta-analysis supports current guidelines advising the FFR performance for CAD patients, and lesions should only be treated when haemodynamic significance is found. Angiography-guided PCI should be discouraged because the visual estimation of coronary stenosis severity during coronary angiography does not reveal its haemodynamic significance even when performed and analysed by experienced cardiologists. To our knowledge, this meta-analysis is the only one comparing angiography-guided PCI and FFR-guided PCI strategies.

PCI procedures are always associated with many potential serious procedural complications such as restenosis, stent thrombosis, contrast-induced nephropathy and bleeding. PCI should only be performed in cases in which the benefit of revascularisation outweighs the risk of complications, while this benefit is mainly attributable to the reduction of myocardial ischaemia. FFR was first described by Pijls et $a l^{3}$ and De Bruyne et al ${ }^{14}$ Randomised studies have resulted in the consensus that PCI should be performed selectively in coronary lesions in which FFR is positive.

The prospective, randomised, multicenter FAME study has shown a favourable 2-year clinical outcome of FFR-guided PCI compared with angiography-guided PCI in a broad population of patients. This is the only randomised study incorporated into our meta-analysis. In this study, 1005 CAD patients with multivessel disease were randomly assigned to angiography-guided

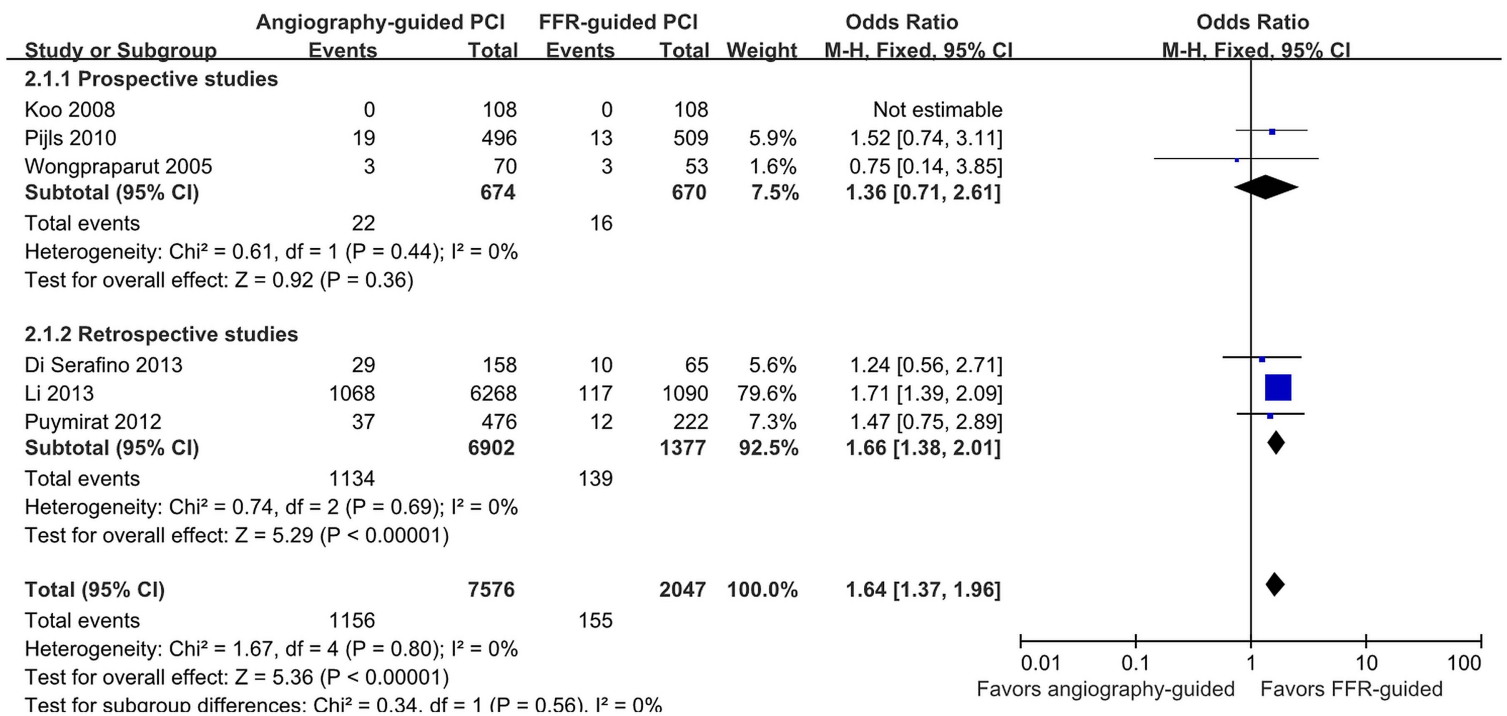

Figure 3 Angiography-guided percutaneous coronary intervention (PCI) versus fractional flow reserve-guided $\mathrm{PCl}$ death. 


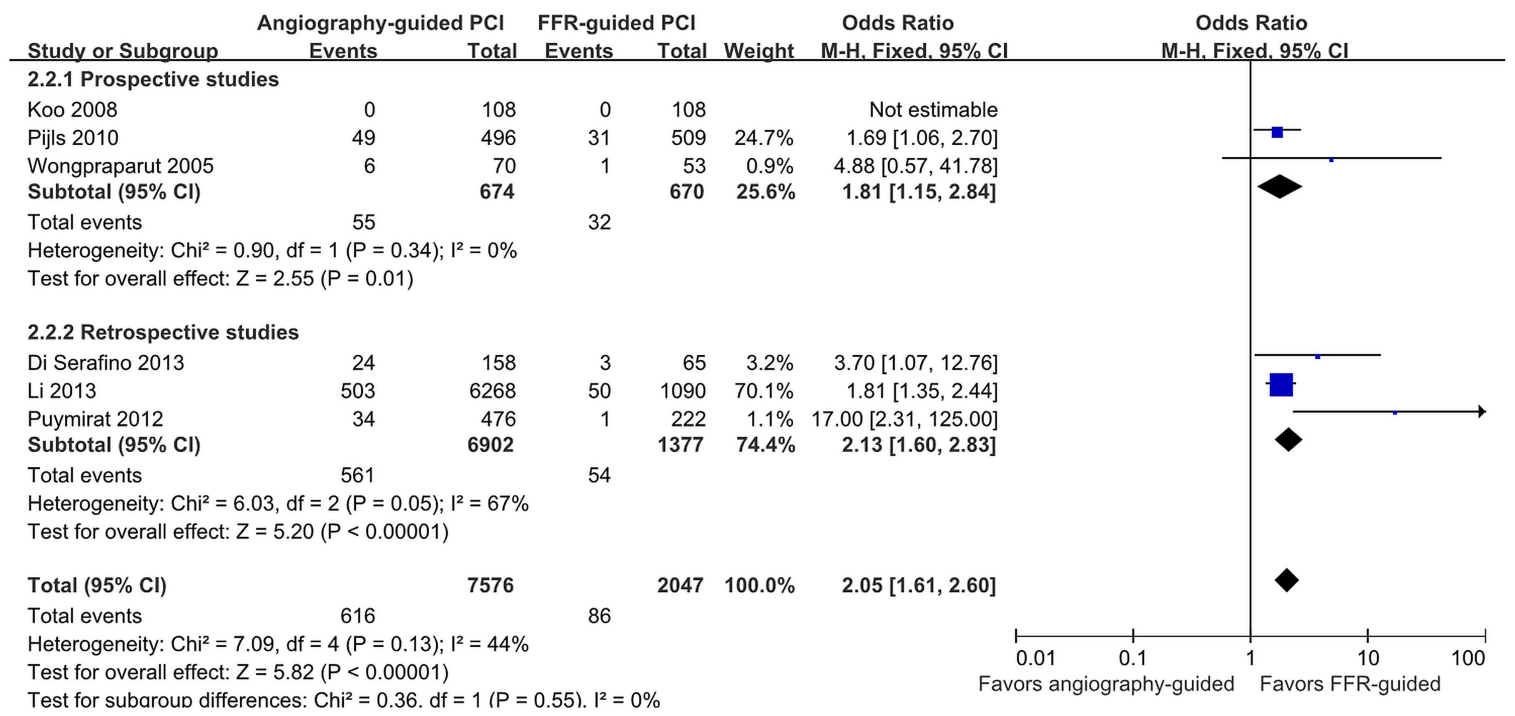

Figure 4 Angiography-guided percutaneous coronary intervention ( $\mathrm{PCl}$ ) versus fractional flow reserve-guided $\mathrm{PCI}$ myocardial infarction.

\begin{tabular}{|c|c|c|c|c|c|c|c|c|c|}
\hline Study or Subgroup & \multicolumn{2}{|c|}{ Angiography-guided PCI } & \multicolumn{2}{|c|}{ FFR-quided PCI } & & $\begin{array}{l}\text { Odds Ratio } \\
\text { M-H. Fixed } 95 \% \mathrm{Cl}\end{array}$ & \multicolumn{3}{|c|}{$\begin{array}{l}\text { Odds Ratio } \\
\text { M-H. Fixed } 95 \% \mathrm{Cl}\end{array}$} \\
\hline \multicolumn{10}{|c|}{ 2.3.1 Prospective studies } \\
\hline Koo 2008 & 4 & 108 & 5 & 108 & $1.3 \%$ & $0.79[0.21,3.03]$ & & & \\
\hline Pijls 2010 & 63 & 496 & 54 & 509 & $12.6 \%$ & $1.23[0.83,1.80]$ & & $=$ & \\
\hline Wongpraparut 2005 & 16 & 70 & 3 & 53 & $0.7 \%$ & $4.94[1.36,17.97]$ & & & \\
\hline Subtotal $(95 \% \mathrm{Cl})$ & & 674 & & 670 & $14.7 \%$ & $1.37[0.96,1.94]$ & & 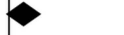 & \\
\hline Total events & 83 & & 62 & & & & & & \\
\hline \multicolumn{10}{|c|}{ Heterogeneity: $\mathrm{Chi}^{2}=4.74, \mathrm{df}=2(\mathrm{P}=0.09) ; \mathrm{I}^{2}=58 \%$} \\
\hline \multicolumn{10}{|c|}{ Test for overall effect: $Z=1.76(P=0.08)$} \\
\hline \multicolumn{10}{|c|}{ 2.3.2 Retrospective studies } \\
\hline Di Serafino 2013 & 33 & 158 & 9 & 65 & $2.7 \%$ & $1.64[0.74,3.66]$ & & + & \\
\hline Li 2013 & 1344 & 6268 & 209 & 1090 & $75.9 \%$ & $1.15[0.98,1.35]$ & & & \\
\hline Puymirat 2012 & 86 & 476 & 22 & 222 & $6.7 \%$ & $2.00[1.22,3.30]$ & & & \\
\hline Subtotal $(95 \% \mathrm{Cl})$ & & 6902 & & 1377 & $85.3 \%$ & $1.23[1.06,1.43]$ & & $\downarrow$ & \\
\hline Total events & 1463 & & 240 & & & & & & \\
\hline \multirow{2}{*}{\multicolumn{10}{|c|}{$\begin{array}{l}\text { Heterogeneity: } \mathrm{Chi}^{2}=4.84, \mathrm{df}=2(P=0.09) ; I^{2}=59 \% \\
\text { Test for overall effect: } Z=2.71(P=0.007)\end{array}$}} \\
\hline & & & & & & & & & \\
\hline Total $(95 \% \mathrm{Cl})$ & & 7576 & & 2047 & $100.0 \%$ & $1.25[1.09,1.44]$ & & $\downarrow$ & \\
\hline Total events & 1546 & & 302 & & & & & & \\
\hline Heterogeneity: $\mathrm{Chi}^{2}=$ & 9.70, $d f=5(P=$ & ${ }^{2}=48 \%$ & & & & & $0.01 \quad 0.1$ & & $10 \quad 100$ \\
\hline Test for overall effect: & $Z=3.17(P=0$. & & & & & Favo & ors angiography-guided & Favors FFF & R-guided \\
\hline
\end{tabular}

Figure 5 Angiography-guided percutaneous coronary intervention $(\mathrm{PCl})$ versus fractional flow reserve-guided $\mathrm{PCl}$ repeat revascularisation.

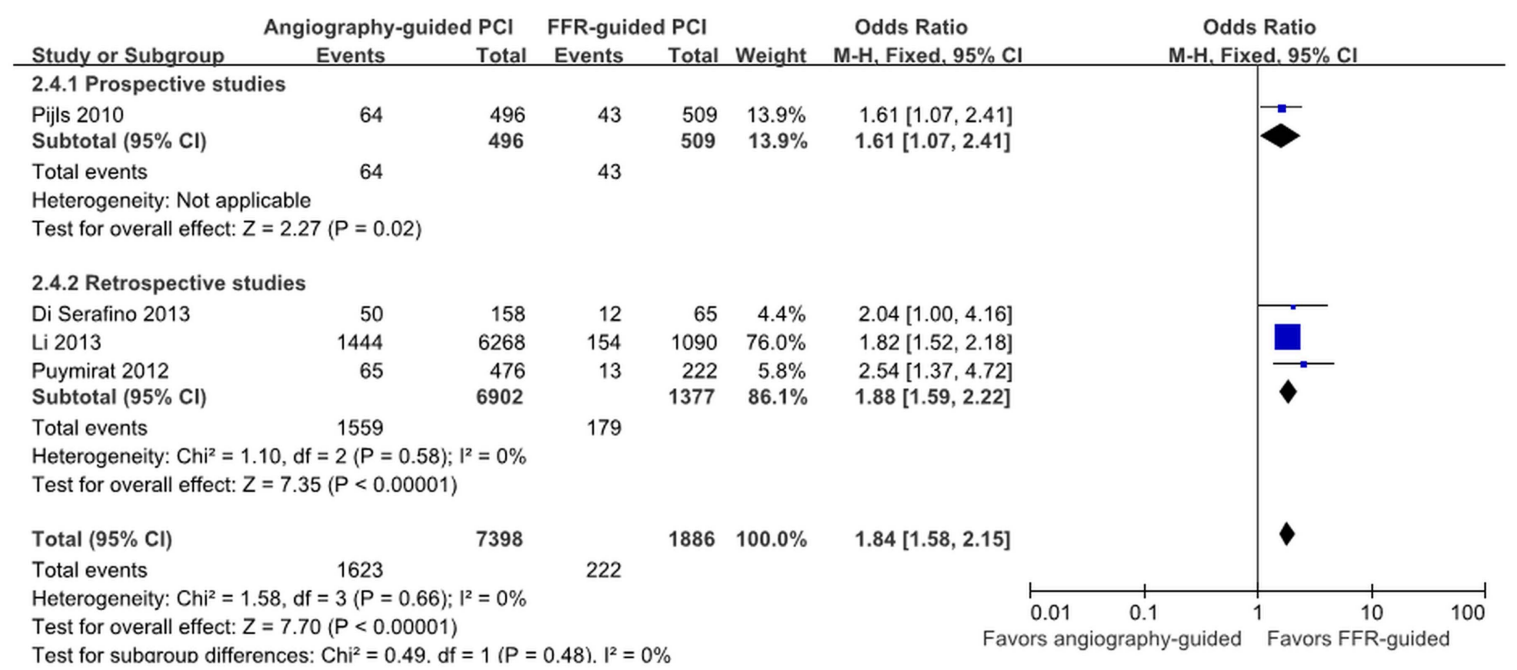

Figure 6 Angiography-guided percutaneous coronary intervention (PCI) versus fractional flow reserve-guided PCI death or myocardial infarction. 


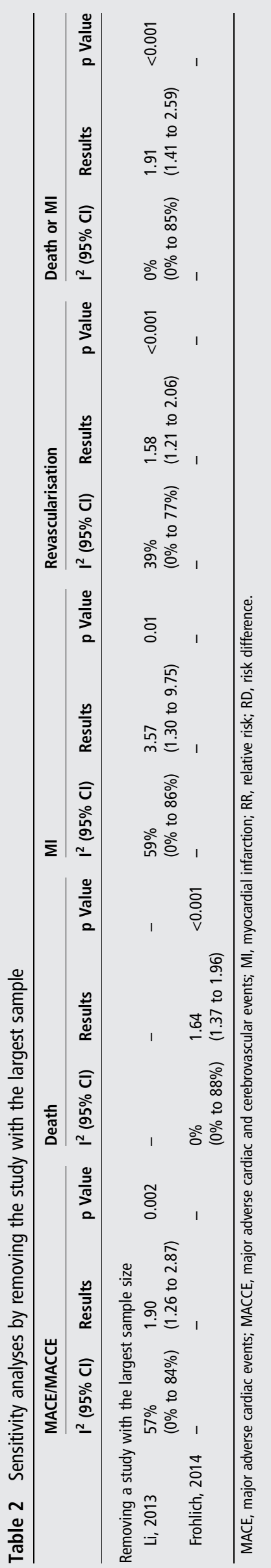

PCI $(n=496)$ or FFR-guided PCI $(n=509)$ groups using an FFR cut-off value of 0.80 as reflecting inducible ischaemia. The routine measurement of FFR during the PCI procedure significantly reduced the rate of MACE $(13.2 \%$ vs $18.3 \%, \mathrm{p}=0.02)$ and death or MI $(7.3 \%$ vs $11.1 \%, \mathrm{p}=0.04)$ at 1 year. Death or MI $(8.4 \%$ vs $12.9 \%, \mathrm{p}=0.02)$ and MI $(6.1 \%$ vs $9.9 \%, \mathrm{p}=0.03)$ were also significantly reduced due to FFR at a 2-year follow-up. The rate of MACE/MACCE for FFR-guided PCI and angiography-guided PCI groups reported in our meta-analysis is even greater $(22.5 \%$ vs $34.8 \%)$ than in the FAME study. The results are in accordance with the 5-year follow-up of the DEFER (FFR to Determine the Appropriateness of Angioplasty in Moderate Coronary Stenosis) study, which demonstrated that patients derived no clinical benefit from the revascularisation of angiographic obstructive lesions ( $>50 \%$ stenosis) that were haemodynamically insignificant based on FFR. ${ }^{15}$

The study conducted by Li et al examined the largest number of patients with FFR-guided interventions. In this retrospective study, 7358 patients referred for PCI at the Mayo Clinic were divided into angiography-guided PCI $(n=6268)$ and FFR-guided PCI $(n=1090)$ group. Overall, the use of FFR was associated with a non-significant lower incidence of death or MI $(p=0.06)$. The long-term outcome was better in the FFR-guided group after excluding patients in whom PCI was deferred in a vessel with FFR between 0.75 and 0.80 .

In previous studies, FFR values ranging between 0.75 and 0.80 were considered to be in a 'grey zone' and required clinical judgment for decision making regarding revascularisation. A study published recently, studied 720 patients retrospectively who deferred revascularisation. ${ }^{16}$ No difference was detected when comparing clinical outcomes between the grey zone and borderline FFR groups (0.80-0.85). Lesions with deferred revascularisation because of borderline FFR were associated with a higher risk of deferred lesion intervention compared with lesions with a non-borderline FFR (>0.85). The DEFER study showed that performing PCI in lesions with FFR $\geq 0.75$ does not provide clinical benefit over not performing PCI, but it did not demonstrate that performing PCI in lesions with FFR $<0.75$ reduces events compared with deferring PCI.

FFR-guided PCI strategy improves outcomes and reduces the number of stents used. However, FFR is not widely applied in clinical practice. Less than $10 \%$ of coronary procedures use adjunctive FFR to guide management due to various practical limitations of FFR measurement such as the extra time and expense associated with the use of a coronary pressure wire and the need for the intracoronary or intravenous administration of adenosine. ${ }^{17}$ In clinical scenarios, many factors may influence the physician's decision whether to perform revascularisation including patient preference, compliance with medication, bleeding tendency, the complexity of the coronary lesion and various other factors, which may all lead to a decision that can be discordant with the FFR result. Furthermore, there are logistic and economic reasons to perform angiography-guided PCI as it may limit procedures and equipment costs. Sant'Anna et al demonstrated that FFR routinely used for decision making modifies treatment decisions in $32 \%$ of all stenoses and $48 \%$ of all patients, compared with decisions based on angiography alone.

FFR measurement may not always accurately reflect the true significance of a coronary stenosis. Common examples are when using submaximal hyperaemia or a large guiding catheter that may obstruct the ostium of the coronary artery and interfere with maximal blood flow.

The recent introduction of a novel computational method has enabled the calculation of $\mathrm{FFR}_{\mathrm{CT}}$ from cardiac CT imaging data 
without the need for additional imaging, medication, or modification of CT acquisition protocols to determine the functional significance of coronary artery lesions. Its diagnostic accuracy has been evaluated in three prospective, multicenter studies using measured FFR as the reference standard. ${ }^{18-20}$ This would greatly help patients and their physicians avoid unnecessary procedures, and will result in significant cost savings to the health system.

In patients with stable CAD and objectively documented myocardial ischaemia diagnosed by stress testing or FFR, a collaborative meta-analysis of contemporary randomised clinical trials including five trials ${ }^{21-25}$ and 4064 patients indicated that PCI with medical therapy (MT) was not associated with a reduction in death, non-fatal MI, unplanned revascularisation, or angina compared with MT alone, ${ }^{26}$ which suggests that the relationship between ischaemia and mortality is not altered by revascularisation of coronary stenoses. The common practice of ischaemiaguided revascularisation (either using non-invasive testing techniques or FFR) where the presence of myocardial ischaemia routinely determines patient selection for coronary angiography and revascularisation should be addressed. Prevention by risk factor control remains the most effective way of reducing adverse outcomes through healthy lifestyle and medications.

\section{Study limitations}

Seven studies including 49517 patients met our inclusion criteria. The issue of bias and heterogeneity might not be fully investigated using such small sample size. Because of limited randomised data, this meta-analysis included both prospective and retrospective studies. Therefore, more than half the included studies were retrospective analyses. The inclusion of studies with different designs and retrospective studies is likely to have induced heterogeneity in the results, as illustrated by the differences found between prospective and retrospective studies. Furthermore, lesions of different characteristics were incorporated because limited studies were found comparing angiography-guided and FFR-guided PCI. TVR was only reported in three studies. Only one study performed by Pijls et $a l^{5}$ included all enrolled patients in their analysis of

Key messages

\section{What is already known on this subject?}

Fractional flow reserve (FFR) is recommended to guide percutaneous coronary revascularisation. However, the adoption of FFR into daily clinical practice has been limited due to the invasive nature of the procedure, the need for pharmacologic vasodilation, and risks related to the instrumentation of the coronary arteries.

\section{What might this study add?}

FFR-guided percutaneous coronary intervention $(\mathrm{PCl})$ was associated with lower major adverse cardiac events/major adverse cardiac and cerebrovascular events (OR: $1.71,95 \% \mathrm{Cl}$ 1.31 to 2.23$)$, death (OR: $1.64,95 \% \mathrm{Cl} 1.37$ to 1.96$)$, myocardial infarction (MI) (OR: $2.05,95 \% \mathrm{Cl} 1.61$ to 2.60 ), repeat revascularisation (OR: $1.25,95 \% \mathrm{Cl} 1.09$ to 1.44 ), and death or MI (OR: $1.84,95 \% \mathrm{Cl} 1.58$ to 2.15 ) than angiography-guided $\mathrm{PCl}$ strategy. Percutaneous coronary revascularisation should be determined by FFR results.

How might this impact on clinical practice? This study summarises the importance of FFR, and provides strong evidence for FFR-guided PCI. primary and secondary endpoints according to the intention-totreat (ITT) principle. Frohlich et $a l^{10}$ performed a complete case analysis, and patients with missing values were excluded. The missing data in each study will possible induce heterogeneity and influence the results. The results and conclusions should be interpreted with these limitations in mind.

\section{CONCLUSIONS}

This meta-analysis supports current guidelines advising the FFR-guided PCI strategy for CAD. PCI should only be performed when haemodynamic significance is found. More prospective research should be performed to investigate the efficacy and safety of FFR measurement in different kinds of lesions.

Acknowledgements We would like to thank Jing Li for providing data of interest. Contributors Conceived and designed the experiments: DZ, SL, XS. Performed the experiments: DZ, FY, FX, MZ. Analysed the data: SY, XC. Wrote the paper: DZ, XS.

Funding This work was supported by the State Science and Technology Support Program (No. 2011BAl11B05) and Beijing Municipal Science and Technology Project (Z141107002514138)

Competing interests None.

Patient consent Obtained.

Provenance and peer review Not commissioned; externally peer reviewed.

Open Access This is an Open Access article distributed in accordance with the Creative Commons Attribution Non Commercial (CC BY-NC 4.0) license, which permits others to distribute, remix, adapt, build upon this work non-commercially, and license their derivative works on different terms, provided the original work is properly cited and the use is non-commercial. See: http://creativecommons.org/ licenses/by-nc/4.0/

\section{REFERENCES}

1 Mathers CD, Loncar D. Projections of global mortality and burden of disease from 2002 to 2030. PLoS Med 2006:3:e442.

2 Shaw LJ, Iskandrian AE. Prognostic value of gated myocardial perfusion SPECT. J Nucl Cardiol 2004;11:171-85.

3 Pijls $\mathrm{NH}$, van Son JA, Kirkeeide RL, et al. Experimental basis of determining maximum coronary, myocardial, and collateral blood flow by pressure measurements for assessing functional stenosis severity before and after percutaneous transluminal coronary angioplasty. Circulation 1993;87:1354-67.

4 Pijls NH, Van Gelder B, Van der Voort P, et al. Fractional flow reserve. A useful index to evaluate the influence of an epicardial coronary stenosis on myocardial blood flow. Circulation 1995:92:3183-93.

5 Pijls NH, Fearon WF, Tonino PA, et al. Fractional flow reserve versus angiography for guiding percutaneous coronary intervention in patients with multivessel coronary artery disease: 2-year follow-up of the FAME (Fractional Flow Reserve Versus Angiography for Multivessel Evaluation) study. J Am Coll Cardiol 2010;56:177-84.

6 Wijns W, Kolh P, Danchin N, et al. Guidelines on myocardial revascularization. Eur Heart J 2010;31:2501-55.

7 Levine GN, Bates ER, Blankenship JC, et al. 2011 ACCF/AHA/SCAI Guideline for Percutaneous Coronary Intervention. A report of the American College of Cardiology Foundation/American Heart Association Task Force on Practice Guidelines and the Society for Cardiovascular Angiography and Interventions. J Am Coll Cardiol 2011;58:e44-122.

8 Koo BK, Park KW, Kang HJ, et al. Physiological evaluation of the provisional side-branch intervention strategy for bifurcation lesions using fractional flow reserve. Eur Heart J 2008;29:726-32.

9 Wongpraparut N, Yalamanchili V, Pasnoori V, et al. Thirty-month outcome after fractional flow reserve-guided versus conventional multivessel percutaneous coronary intervention. Am J Cardiol 2005;96:877-84.

10 Frohlich GM, Redwood S, Rakhit R, et al. Long-term survival in patients undergoing percutaneous interventions with or without intracoronary pressure wire guidance or intracoronary ultrasonographic imaging: a large cohort study. JAMA Intern Med 2014;174:1360-6.

11 Di Serafino L, De Bruyne B, Mangiacapra F, et al. Long-term clinical outcome after fractional flow reserve- versus angio-guided percutaneous coronary intervention in patients with intermediate stenosis of coronary artery bypass grafts. Am Heart $J$ 2013;166:110-18.

12 Li J, Elrashidi MY, Flammer AJ, et al. Long-term outcomes of fractional flow reserve-guided vs. angiography-guided percutaneous coronary intervention in contemporary practice. Eur Heart J 2013;34:1375-83. 
13 Puymirat E, Peace A, Mangiacapra F, et al. Long-term clinical outcome after fractional flow reserve-guided percutaneous coronary revascularization in patients with small-vessel disease. Circ Cardiovasc Interv 2012;5:62-8.

14 De Bruyne B, Baudhuin T, Melin JA, et al. Coronary flow reserve calculated from pressure measurements in humans. Validation with positron emission tomography. Circulation 1994;89:1013-22.

15 Pijls NH, van Schaardenburgh P, Manoharan G, et al. Percutaneous coronary intervention of functionally nonsignificant stenosis: 5-year follow-up of the DEFER Study. J Am Coll Cardiol 2007;49:2105-11.

16 Depta JP, Patel JS, Novak E, et al. Outcomes of coronary stenoses deferred revascularization for borderline versus nonborderline fractional flow reserve values. Am J Cardiol 2014;113:1788-93.

17 Morris PD, Ryan D, Morton AC, et al. Virtual fractional flow reserve from coronary angiography: modeling the significance of coronary lesions: results from the VIRTU-1 (VIRTUal Fractional Flow Reserve From Coronary Angiography) study. JACC Cardiovasc Interv 2013;6:149-57.

18 Koo BK, Erglis A, Doh JH, et al. Diagnosis of ischemia-causing coronary stenoses by noninvasive fractional flow reserve computed from coronary computed tomographic angiograms. Results from the prospective multicenter DISCOVER-FLOW (Diagnosis of Ischemia-Causing Stenoses Obtained Via Noninvasive Fractional Flow Reserve) study. J Am Coll Cardiol 2011;58:1989-97.

19 Min JK, Leipsic J, Pencina MJ, et al. Diagnostic accuracy of fractional flow reserve from anatomic CT angiography. JAMA 2012;308:1237-45.
20 Norgaard BL, Leipsic J, Gaur S, et al. Diagnostic performance of noninvasive fractional flow reserve derived from coronary computed tomography angiography in suspected coronary artery disease: the NXT trial (analysis of coronary blood flow using CT angiography: next steps). J Am Coll Cardiol 2014;63:1145-55.

21 Hueb W, Lopes NH, Gersh BJ, et al. Five-year follow-up of the Medicine, Angioplasty, or Surgery Study (MASS II): a randomized controlled clinical trial of 3 therapeutic strategies for multivessel coronary artery disease. Circulation 2007;115:1082-9.

22 Frye RL, August P, Brooks MM, et al. A randomized trial of therapies for type 2 diabetes and coronary artery disease. N Engl J Med 2009;360:2503-15.

23 Hambrecht $R$, Walther $C$, Mobius-Winkler $S$, et al. Percutaneous coronary angioplasty compared with exercise training in patients with stable coronary artery disease: a randomized trial. Circulation 2004;109:1371-8.

24 De Bruyne B, Pijls NH, Kalesan B, et al. Fractional flow reserve-guided PCl versus medical therapy in stable coronary disease. $N$ Engl J Med 2012;367:991-1001.

25 Boden WE, O'Rourke RA, Teo KK, et al. Optimal medical therapy with or without $\mathrm{PCl}$ for stable coronary disease. N Engl J Med 2007;356:1503-16.

26 Stergiopoulos K, Boden WE, Hartigan P, et al. Percutaneous coronary intervention outcomes in patients with stable obstructive coronary artery disease and myocardial ischemia: a collaborative meta-analysis of contemporary randomized clinical trials. JAMA Intern Med 2014;174:232-40. 